\title{
Optimization of Alkali Catalyzed Transesterification of Safflower Oil for Production of Biodiesel
}

\author{
M. C. Math and K. N. Chandrashekhara \\ Department of Thermal Power Engineering, Visvesvaraya Technological University Post Graduation Center, Mysuru, \\ Karnataka 570 029, India
}

Correspondence should be addressed to M. C. Math; mcmath1018@yahoo.com

Received 14 November 2015; Revised 17 January 2016; Accepted 20 January 2016

Academic Editor: Wei Du

Copyright (c) 2016 M. C. Math and K. N. Chandrashekhara. This is an open access article distributed under the Creative Commons Attribution License, which permits unrestricted use, distribution, and reproduction in any medium, provided the original work is properly cited.

\begin{abstract}
The Central Composite Design is used for the optimization of alkaline catalyzed transesterification parameters such as methanol quantity, catalytic concentration, and rotational speed by keeping the temperature and reaction time constant. The Central Composite Design method is employed to get the maximum safflower oil methyl ester yield. The combined effects of catalyst concentration, rotational speed, and molar ratio of alcohol to oil were investigated and optimized using response surface methodology. A statistical model has predicted the maximum yield of safflower oil methyl ester ( $94.69 \%$ volume of oil) parameters such as catalyst concentration $(0.6$ grams $)$, methanol amount $(30 \mathrm{~mL})$, rotational speed $(600 \mathrm{rpm})$, and keeping constant reaction temperature $\left(55^{\circ} \mathrm{C}\right.$ to $65^{\circ} \mathrm{C}$ ) and reaction time (60 minutes). Experimental maximum yield of $91.66 \%$ was obtained at above parameters. XLSTAT is used to generate a linear model to predict the methyl ester yield as a function of methanol quantity, catalyst concentration, and rotational speed by keeping constant reaction temperature $\left(55^{\circ} \mathrm{C}\right.$ to $\left.65^{\circ} \mathrm{C}\right)$ and reaction time $(60$ minutes). MINITAB is used to draw the $3 \mathrm{D}$ response surface plot and $2 \mathrm{D}$ contour plot to predict the maximum biodiesel yield.
\end{abstract}

\section{Introduction}

Energy consumption is the basic requirements for human existence. Fossil fuels are the main suppliers of energy for today's world. Due to increasing global warming and consumption of fossil fuels leading to huge petroleum crisis, hence there is a need to find out the alternative renewable energy sources for fuel generation $[1,2]$. Oil crisis during 1971 in the world is also the notable reason for finding the alternative sources for the conventional oils. The highest percentage of total energy output in the world is obtained from fossil fuels and they are finite resources. $79 \%$ of the Indian crude oil requirement is met by imports. It is reported that India has consumed 73500 million tons of diesel oil and 16335 million tons of petrol for the year 2013-14. The values of petroleum products imported during 1913-1914 were 16.718 million metric tons (MMT) valued at Rs 74,605 crore and during 2012-2013 petroleum products were 15.774 MMT valued at Rs 68363 crore. Imports of petroleum products increased by $5.98 \%$ in terms of quantity and increased by $9.13 \%$ in terms of values. The cost of the conventional diesel oil fluctuates day by day and it affects the economies of oil importing countries [3]. So, by using conventional diesel oil that leads to the formation of high $\mathrm{HC}, \mathrm{NO}_{x}, \mathrm{CO}$, and particulate matter it has greater effect on environmental changes causing the severe problems on human beings. Use of conventional diesel oil increases the global warming, greenhouse effect, unseasonable rains, and acid rain formation [4-6]. The most practical way to reach this demand is by using alternative fuels. The alternative energy or fuel is renewable energy sources and it is free energy sources that have no undesirable consequences on the environment $[7,8]$. Among the various alternative energy sources, biodiesel exhibits a great potential. The term biodiesel commonly refers to oxygenated diesel fuel and it is made from various renewable feed stocks by the conversion of the triglycerides to respective esters. Biodiesel consists of long chain fatty acids of monoalkyl esters of nontoxic, biodegradable, and sulphur-free renewable energy 
and it is obtained from the conversion of triglycerides to esters by transesterification with alcohol in the presence of acid or base catalyst.

The transesterification process is a very important process in the production of biodiesel because it reduces the viscosity of vegetable oils and brings it nearer to that of conventional diesel oil, thus avoiding the engine related problems and increasing the engine life. Alkali catalyzed transesterification reaction is the most adopting methods for production of biodiesel because it is simple to extract the respective esters. This process is only applicable for oils that have low free fatty acid level $(<4)$ and acid catalyst transesterification process is applicable only for high free fatty acid level $(>4)$ oils.

Enzymatic catalyzed transesterification can also be used for the production of biodiesel from low grade feedstock like used cooking oil, animal fat, and so forth. This process is carried out in the presence of enzyme such as lipase. This process has many advantages over the conventional transesterification process like generation of zero byproduct, no difficulty in separation, and requiring moderate reaction conditions. However, yield, reaction times, and costs are still critical compared to alkaline catalyzed transesterification reaction $[9,10]$.

Noncatalyzed Biox transesterification process is a new method available for the production of biodiesel. In transesterification reaction biodiesel yield is slow because of the low solubility of alcohol in oil. This problem is solved by using a cosolvent, tetrahydrofuran, to stabilize methanol [11, 12].

Noncatalyzed supercritical methanol method is the most recent method available for producing biodiesel. This method requires only 4 minutes to complete the reaction but requires high alcohol-oil ratio, high capital cost, and high pressure (80 bar) and temperature $\left(350^{\circ} \mathrm{C}-400^{\circ} \mathrm{C}\right)[13-15]$.

In this present study, experiments have been carried out according to Central Composite Design (CCD) to understand the relation between the process variables and biodiesel yield by using alkaline base-catalyzed transesterification process. A CCD method was used to find out the optimal experimental conditions for production of biodiesel. CCD has the advantage of predicting response or yield based on a few sets of experimental results in which all the parameters varied within the range.

\section{Materials and Methods}

2.1. Materials. Unrefined low grade safflower oil is kindly supplied by the supplier and methanol was used as reactants and $\mathrm{NaOH}$ was used as catalyst for the transesterification process.

2.2. Methods. Free fatty acid level was found out by using the titration method and it was found to be less than $4 \%$. The alkaline stage transesterification process was used for the production of biodiesel. Sodium hydroxide is used as an alkaline catalyst transesterification process because it is cheaper and reacts faster than acid catalyst.

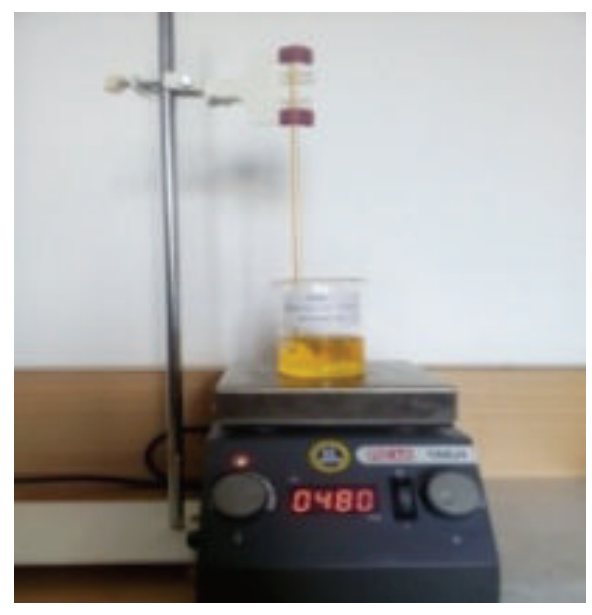

FIGURE 1: Magnetic stirrer with hot plate.

2.2.1. Transesterification. The low grade safflower oil was converted into methyl esters through alkaline base-catalyzed transesterification process with methanol in the presence of $\mathrm{NaOH}$ catalyst. Before the transesterification process, the dust particle and other impurities have been removed from the low grade safflower oil by filtration with cloth filter. After that process, take the required quantity of low grade safflower oil and add required amount of methanol and $\mathrm{NaOH}$ to $1000 \mathrm{~mL}$ beaker placed on a magnetic stirrer having hot plate (Figure 1) with continuous heating and rotational system. The thermometer is placed inside the beaker such that it is just in contact with the surface of the oil. This mixture was stirred and heated to $60^{\circ} \mathrm{C}$ for 1 hour and then allowed to cool to attain room temperature for 8 to 10 hours [16]. Then the biodiesel and glycerol layers separated in separating funnel. Finally, methyl esters of low grade safflower oil were purified with normal water and heating to $90^{\circ} \mathrm{C}$ by using a magnetic stirrer with hot plate.

\subsubsection{Experimental Design}

(1) Parameter Design Methodology. In order to optimize the transesterification process parameters a five-level-threefactor CCD has been used. Three control parameters such as methanol $(D)$ in $\mathrm{mL}$, sodium hydroxide $(E)$ in grams, and rotational speed $(F)$ in RPM have been selected for optimization of biodiesel yield. Each of the three control parameters has been treated at five levels. Table 1 shows the code and uncoded levels of independent variables.

(2) Design of Experiments. Table 2 shows that the experimental matrix for CCD and biodiesel yield for alkaline catalyzed transesterification process. Twenty experiments have been conducted by keeping constant reaction temperature $\left(55^{\circ} \mathrm{C}\right.$ to $60^{\circ} \mathrm{C}$ ) and reaction time (60 minutes).

2.3. Experimental Procedure. Sample (Figure 2) has been taken into the beaker and it is maintained at the constant 
TABLE 1: Independent parameter and levels used in CCD.

\begin{tabular}{|c|c|c|c|c|c|}
\hline \multirow[b]{2}{*}{ Parameters } & \multicolumn{5}{|c|}{ Levels } \\
\hline & $\begin{array}{c}-1.68 \\
(-\alpha)\end{array}$ & -1 & 0 & 1 & $\begin{array}{c}+1.68 \\
(+\alpha)\end{array}$ \\
\hline $\mathrm{CH}_{3} \mathrm{OH}$ in $\mathrm{mL}(D)$ & 16.6 & 20 & 25 & 30 & 33.4 \\
\hline $\mathrm{NaOH}$ concentration $(E)$ in grams & 0.464 & 0.6 & 0.8 & 1.0 & 1.136 \\
\hline Rotational speed in RPM $(F)$ & 332 & 400 & 500 & 600 & 768 \\
\hline
\end{tabular}

temperature $\left(55^{\circ} \mathrm{C}\right.$ to $\left.60^{\circ} \mathrm{C}\right)$ and reaction time (60 minutes). The sodium methoxide solution was prepared by dissolving the required amount of $\mathrm{NaOH}$ in a certain amount of methanol. Half of prepared sodium methoxide is added to the sample and continues rotational speed and heating with a magnetic stirrer having a hot plate (Figure 1) for 10 to 15 minutes. Then add remaining half of the prepared sodium methoxide solution into the sample for 45 to 50 minutes with continuous rotational speed and heating. A similar procedure is carried out for 20 experiments which have been conducted as per the experimental matrix shown in Table 2. On completion of reaction, the mixture is allowed to cool to room temperature and it is falling into two layers. Top one layer is crude safflower oil methyl ester and bottom one is crude glycerin. Figures 3, 4, and 5 show optimized samples which were obtained as per Table 2 . The crude safflower oil methyl ester was washed twice with water to bring the $\mathrm{pH}$ to 7.

2.4. Statistical Analysis. The experimental data have been analyzed with XLSTAT for quadratic least square technique procedure using (1). In this work, XLSTAT for quadratic least square technique with MINITAB software have been used in the regression analysis and analysis of variance (ANOVA) and to generate surface plots using the fitted quadratic polynomial equation obtained from regression analysis (2). Few experiments have been conducted to validate the equation using a combination of the independent variables. Selected variables are within the experimental range

$$
\begin{aligned}
Y= & \beta_{0}+\sum_{i=1}^{n} \beta_{i} X_{i}+\sum_{j=1}^{n} \beta_{j} X_{j}+\sum_{k=1}^{n} \beta_{k} X_{k}+\sum_{i}^{n} \sum_{j}^{n} \beta_{i j} X_{i} X_{j} \\
& +\sum_{i}^{n} \sum_{k}^{n} \beta_{0} X_{i} X_{k}+\sum_{j}^{n} \sum_{k}^{n} \beta_{0} X_{j} X_{k}+\sum_{i=1}^{n} \beta_{i i} X_{i}^{2} \\
& +\sum_{j=1}^{n} \beta_{j j} X_{j}^{2}+\sum_{k=1}^{n} \beta_{k k} X_{k}^{2}
\end{aligned}
$$

where $Y$ is the response variable; $X_{i}, X_{j}$, and $X_{k}$ are coded independent variables; $\beta_{0}, \beta_{i}, \beta_{i i}, \beta_{i j}$ and $\beta_{i k}$ are the intercept, linear, quadratic, and interaction constant coefficients, respectively; and $n$ is the number of factors studied and it optimized in the experiment. The regression model has been found to be highly significant with the correction coefficients (Table 3 ) of determination of $R^{2}$ having a value of 0.909 . The predicted model for a percentage of safflower oil methyl esters

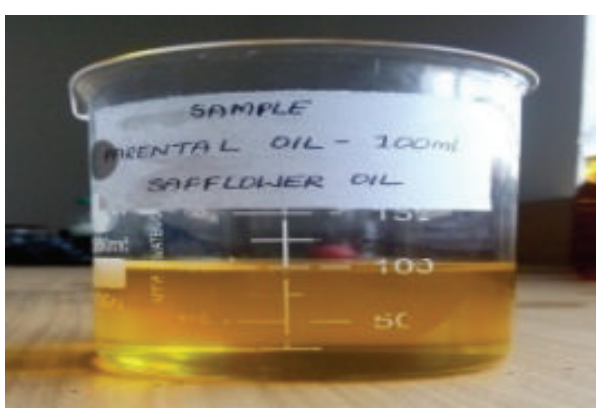

Figure 2: Sample for test.

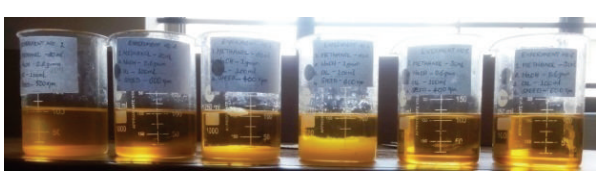

Figure 3: Optimized samples 1-6.

yield in terms of coded factors has been given in the following $[17,18]$ :

$$
\begin{aligned}
Y= & 86.27+2.80 * X_{1}-8.54 * X_{2}-2.72 * X_{3}-0.52 \\
& * X_{1}^{2}-5.20 * X_{2}^{2}+0.67 * X_{3}^{2}+1.90 * X_{1} \\
& * X_{2}+3.26 * X_{1} * X_{3}-3.47 * X_{2} * X_{3}
\end{aligned}
$$

A statistical model (2) predicted that the maximum safflower oil methyl ester (94.694) yield has been obtained at the optimized methanol quantity (30), catalyst (0.6), and rotational speed (600). Experimentally, yield (91.66) has been obtained at the above parameters. Extracting the biodiesel of safflower oil by utilizing these values in mass production has been shown (Plate 3.8 and Plate 3.9).

\section{Result and Discussion}

3.1. Effect of Methanol and $\mathrm{NaOH}$ on Experimental Yield. Figure 6 shows the 3D response surface and 2D contour plot between methanol quantity and concentration of $\mathrm{NaOH}$ for different fixed parameter. From Figure 6 it can be seen that yield (\%) increases with the increase in the quantity of methanol in concentration of $\mathrm{NaOH}$. This has reached the maximum yield $91.66 \%$ of safflower oil methyl ester at 0.6 gram concentration of $\mathrm{NaOH}$ and $30 \mathrm{~mL}$ of methanol. Then the yield is decreased by an increase in the concentration of $\mathrm{NaOH}$ in quantity of methanol. This has reached the $59.82 \%$ of safflower oil methyl ester yield by increase to 1-gram concentration of $\mathrm{NaOH}$ and $20 \mathrm{~mL}$ of methanol quantity.

This is due to the fact that there is less significant interaction between quantity of methanol and concentration of $\mathrm{NaOH}$ and negative concentration of the quadratic coefficient mostly caused by soap formation side reaction, resulting in a decrease in yield.

3.2. Effect of Methanol and Rotational Speed on Experimental Yield. Figure 7 shows the 3D response surface and 2D 
TABLE 2: Experimental matrix for CCD and results.

\begin{tabular}{|c|c|c|c|c|c|c|c|c|}
\hline \multirow{2}{*}{ Exp. number } & \multirow{2}{*}{$D$} & \multirow{2}{*}{$E$} & \multirow{2}{*}{$F$} & \multirow{2}{*}{$\mathrm{CH}_{3} \mathrm{OH}(\mathrm{mL})$} & \multirow{2}{*}{$\mathrm{NaOH}$ (grams) } & \multirow{2}{*}{ Rotational speed (RPM) } & \multicolumn{2}{|c|}{ Yield (\%) } \\
\hline & & & & & & & Experimental & Predicted \\
\hline 1 & -1 & -1 & -1 & 20 & 0.6 & 400 & 91.07 & 91.390 \\
\hline 2 & -1 & -1 & 1 & 20 & 0.6 & 600 & 83.63 & 86.362 \\
\hline 3 & -1 & 1 & -1 & 20 & 1.0 & 400 & 82.60 & 77.425 \\
\hline 4 & -1 & 1 & 1 & 20 & 1.0 & 600 & 59.82 & 58.518 \\
\hline 5 & 1 & -1 & -1 & 30 & 0.6 & 400 & 87.50 & 86.661 \\
\hline 6 & 1 & -1 & 1 & 30 & 0.6 & 600 & 91.66 & 94.694 \\
\hline 7 & 1 & 1 & -1 & 30 & 1.0 & 400 & 85.18 & 80.307 \\
\hline 8 & 1 & 1 & 1 & 30 & 1.0 & 600 & 76.92 & 74.459 \\
\hline 9 & 0 & 0 & -1.68 & 25 & 0.8 & 332 & 87.50 & 92.751 \\
\hline 10 & 0 & 0 & 1.68 & 25 & 0.8 & 668 & 85.83 & 83.607 \\
\hline 11 & 0 & -1.68 & 0 & 25 & 0.464 & 500 & 90.93 & 85.938 \\
\hline 12 & 0 & 1.68 & 0 & 25 & 1.136 & 500 & 50.00 & 57.180 \\
\hline 13 & -1.68 & 0 & 0 & 16.6 & 0.8 & 500 & 79.09 & 80.094 \\
\hline 14 & 1.68 & 0 & 0 & 33.4 & 0.8 & 500 & 87.50 & 89.523 \\
\hline 15 & 0 & 0 & 0 & 25 & 0.8 & 500 & 86.36 & 86.273 \\
\hline 16 & 0 & 0 & 0 & 25 & 0.8 & 500 & 86.36 & 86.273 \\
\hline 17 & 0 & 0 & 0 & 25 & 0.8 & 500 & 86.36 & 86.273 \\
\hline 18 & 0 & 0 & 0 & 25 & 0.8 & 500 & 86.36 & 86.273 \\
\hline 19 & 0 & 0 & 0 & 25 & 0.8 & 500 & 86.36 & 86.273 \\
\hline 20 & 0 & 0 & 0 & 25 & 0.8 & 500 & 86.36 & 86.273 \\
\hline
\end{tabular}

TABLE 3: Regression coefficient of predicted quadratic polynomial model.

\begin{tabular}{lcccc}
\hline Terms & Coefficients & $\begin{array}{c}\text { Standard } \\
\text { errors }\end{array}$ & Computed $t$-value & $P$ value \\
\hline Linear & & & & \\
$\beta_{0}$ & 86.27 & 1.74 & 49.56 & 0.000 \\
$\beta_{1}$ & 2.80 & 1.16 & 2.43 & 0.036 \\
$\beta_{2}$ & -8.55 & 1.16 & -7.40 & 0.000 \\
$\beta_{3}$ & -2.72 & 1.16 & -2.35 & 0.040 \\
Quadratic & & & & \\
$\beta_{11}$ & -0.52 & 1.12 & -0.46 & 0.655 \\
$\beta_{22}$ & -5.20 & 1.12 & -4.63 & 0.001 \\
$\beta_{33}$ & 0.67 & 1.12 & 0.60 & 0.562 \\
Interaction & & & & \\
$\beta_{12}$ & 1.90 & 1.51 & 1.26 & 0.236 \\
$\beta_{13}$ & 3.26 & 1.51 & 2.16 & 0.056 \\
$\beta_{23}$ & -3.47 & 1.51 & -2.30 & 0.044 \\
$R^{2}$ & 0.909 & & & \\
\hline
\end{tabular}

contour plot between quantity of methanol and rotational speed for different fixed parameter. From Figure 7 it can be seen that yield (\%) increases with the increase in the quantity of methanol and rotational speed. This has reached the maximum methyl ester yield of $91.66 \%$ at $30 \mathrm{~mL}$ of methanol and $600 \mathrm{rpm}$ of rotational speed. Then the yield is decreased by a decrease in quantity of methanol and the increase in the rotational speed. This has reached the $59.82 \%$ of safflower oil

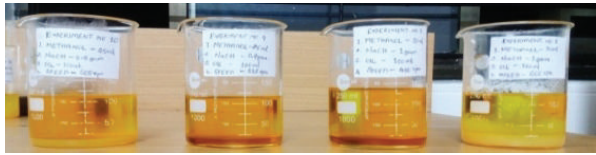

FIGURE 4: Optimized samples 7-10.

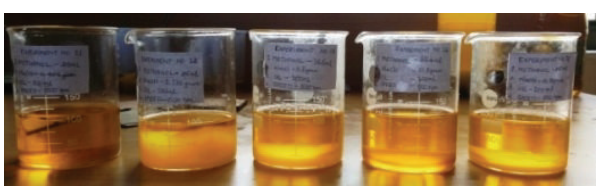

FIGURE 5: Optimized samples 11-15.

methyl ester yield by an increase to $600 \mathrm{rpm}$ rotational speed and $20 \mathrm{~mL}$ methanol to oil. This is due to the fact that there is less significant interaction between quantity of methanol and rotational speed and negative concentration of the quadratic coefficient mostly caused by soap formation side reaction.

If vegetable oil contains free fatty acid, it will react with homogenous base catalysts to form soap and water. The sodium soaps are soluble in the glycerol phase and must be isolated after neutralization by decantation as fatty acids. The loss of esters converted to fatty acids can reach as high as $1 \%$ of the biodiesel production.

3.3. Effect of $\mathrm{NaOH}$ and Rotational Speed on Experimental Yield. Figure 8 shows the 3D response surface and 2D contour plot between the concentration of $\mathrm{NaOH}$ and rotational 


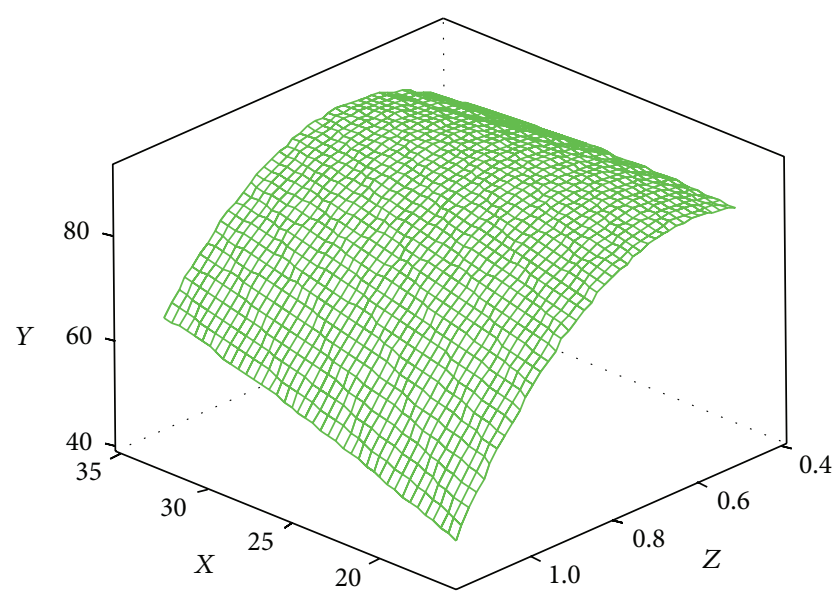

$3 \mathrm{D}$ response surface plot

(a)

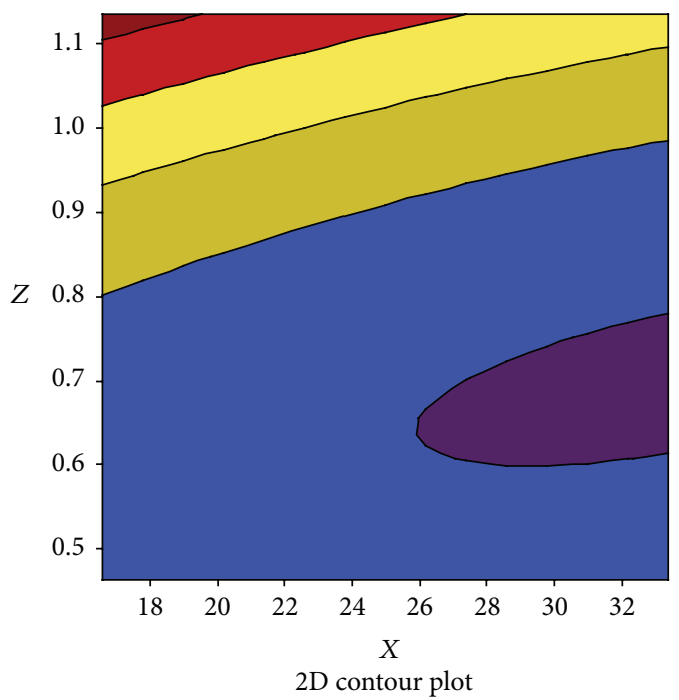

Experimental Yield

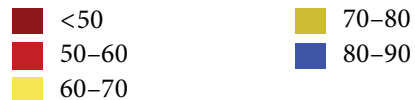

(b)

Figure 6: Effect of methanol $(X)$ and $\mathrm{NaOH}(Z)$ on Experimental Yield $(Y)$.

speed for different fixed parameter. From Figure 8 it can be seen that yield (\%) increases within the rotational speed to the concentration of $\mathrm{NaOH}$. This has reached the maximum safflower oil methyl ester yield $91.66 \%$ at 0.6 -gram concentration of $\mathrm{NaOH}$ and $600 \mathrm{rpm}$ of rotational speed. Then the yield is decreased by an increase in the concentration of $\mathrm{NaOH}$ and increase in the rotational speed. This has reached $59.82 \%$ of safflower oil methyl ester yield by increasing to $600 \mathrm{rpm}$ rotational speed and 1-gram concentration of $\mathrm{NaOH}$. This is due to the fact that there is less significant interaction between the concentration of $\mathrm{NaOH}$ and rotational speed and negative

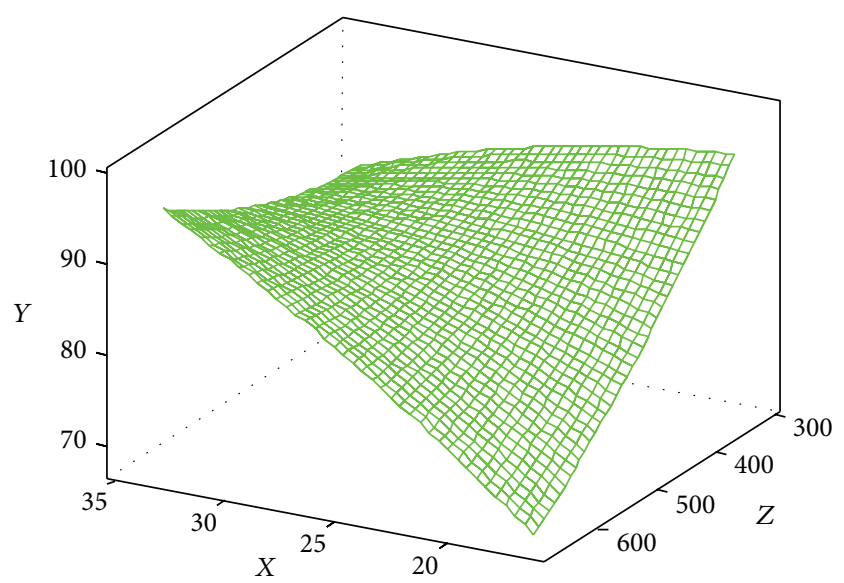

$3 \mathrm{D}$ response surface plot

(a)

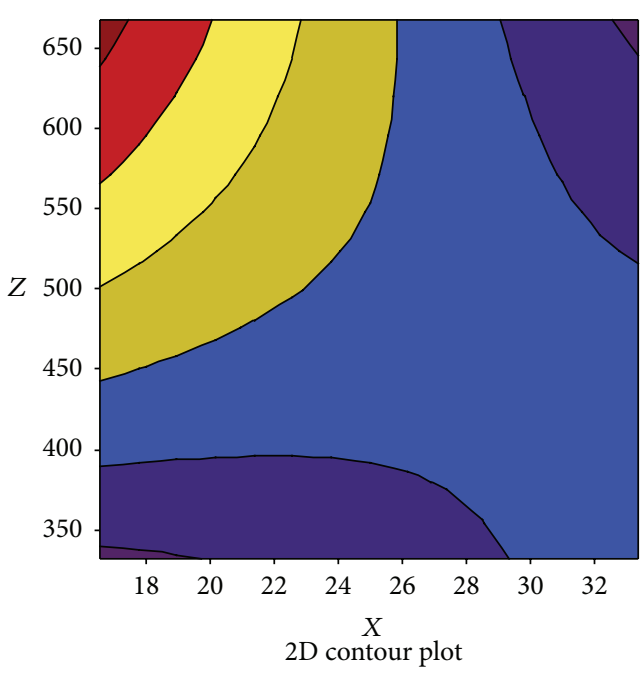

Experimental Yield

\begin{tabular}{ll}
$<70$ & \\
$70-75$ & \\
$75-80-90$ \\
$70-95$ \\
$80-85$ & \\
\hline 95
\end{tabular}

(b)

FIgURE 7: Effect of methanol $(X)$ and rotational speed $(Z)$ on Experimental Yield $(Y)$.

concentration of the quadratic coefficient mostly caused by soap formation side reaction.

\section{Conclusion}

In this present study, experiments have been carried out according to CCD to understand the relation between the process variables and biodiesel yield. CCD method was used to find out the optimal experimental conditions for maximum biodiesel yield. CCD has the advantage of predicting yield based on a few sets of experimental results in which all the parameters varied within the range. A statistical model has predicted the maximum yield of safflower oil methyl ester 


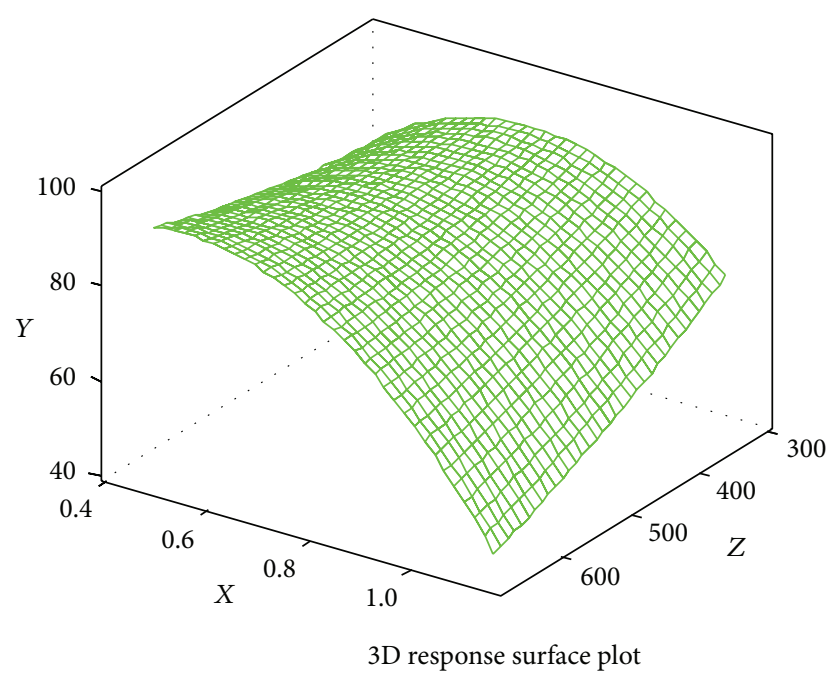

(a)
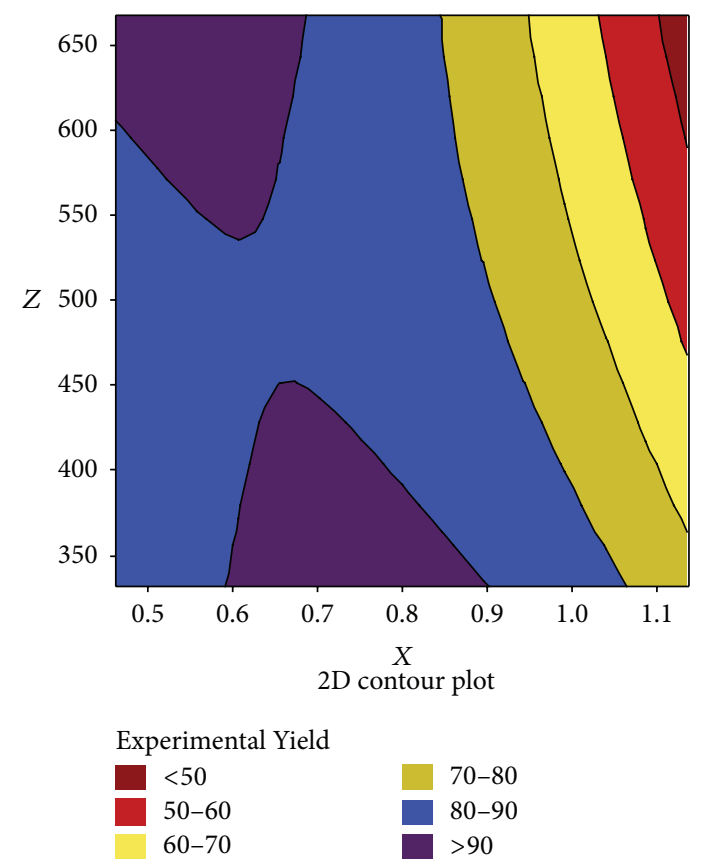

(b)

Figure 8: Effect of $\mathrm{NaOH}(X)$ and rotational speed $(Z)$ on Experimental Yield $(Y)$.

(94.694\% volume of oil) parameters such as catalyst concentration ( 0.6 grams), methanol amount $(30 \mathrm{~mL})$, rotational speed $(600 \mathrm{rpm})$, and keeping constant reaction temperature $\left(55^{\circ} \mathrm{C}\right.$ to $\left.65^{\circ} \mathrm{C}\right)$ and reaction time (60 minutes). Experimental maximum yield of $91.66 \%$ was obtained at above parameters.

\section{Conflict of Interests}

The authors declare that there is no conflict of interests regarding the publication of this paper.

\section{Acknowledgment}

The authors would like to express their appreciation to the Vision Group on Science and Technology (Department of Information Technology, Biotechnology and Science \& Technology), Government of Karnataka, for providing funding under K-FIST Level 1 Grant (GRD 349).

\section{References}

[1] C. C. Enweremadu and M. M. Mbarawa, "Technical aspects of production and analysis of biodiesel from used cooking oil-a review," Renewable and Sustainable Energy Reviews, vol. 13, no. 9, pp. 2205-2224, 2009.

[2] S. A. Basha, K. R. Gopal, and S. Jebaraj, "A review on biodiesel production, combustion, emissions and performance," Renewable and Sustainable Energy Reviews, vol. 13, no. 6-7, pp. 1628$1634,2009$.

[3] Indian petroleum and natural gas statistics 2013-2014, Government of India Ministry of Petroleum \& Natural Gas Economics and Statistics Division, New Delhi, India.

[4] P. K. Sahoo, L. M. Das, M. K. G. Babu, and S. N. Naik, "Biodiesel development from high acid value polanga seed oil and performance evaluation in a CI engine," Fuel, vol. 86, no. 3, pp. 448-454, 2007.

[5] G. Vicente, M. Martínez, and J. Aracil, "Integrated biodiesel production: a comparison of different homogeneous catalysts systems," Bioresource Technology, vol. 92, no. 3, pp. 297-305, 2004.

[6] A. N. Ozsezen, M. Canakci, A. Turkcan, and C. Sayin, "Performance and combustion characteristics of a DI diesel engine fueled with waste palm oil and canola oil methyl esters," Fuel, vol. 88, no. 4, pp. 629-636, 2009.

[7] J.-Z. Yin, M. Xiao, and J.-B. Song, "Biodiesel from soybean oil in supercritical methanol with co-solvent," Energy Conversion and Management, vol. 49, no. 5, pp. 908-912, 2008.

[8] A. Demirbas, "Importance of biodiesel as transportation fuel," Energy Policy, vol. 35, no. 9, pp. 4661-4670, 2007.

[9] M. Canakci and J. H. Van Gerpen, "Biodiesel production from oils and fats with high free fatty acids," Transactions of the American Society of Agricultural Engineers, vol. 44, no. 6, pp. 1429-1436, 2001.

[10] S. Hama, H. Yamaji, M. Kaieda, M. Oda, A. Kondo, and H. Fukuda, "Effect of fatty acid membrane composition on wholecell biocatalysts for biodiesel-fuel production," Biochemical Engineering Journal, vol. 21, no. 2, pp. 155-160, 2004.

[11] M. C. Math, S. P. Kumar, and S. V. Chetty, "Technologies for biodiesel production from used cooking oil-a review," Energy for Sustainable Development, vol. 14, no. 4, pp. 339-345, 2010.

[12] U. Schuchardt, R. Sercheli, and R. M. Vargas, "Transesterification of vegetable oils: a review," Journal of the Brazilian Chemical Society, vol. 9, no. 3, pp. 199-210, 1998.

[13] http://www.bioxcorp.com.

[14] D. Kusdiana and S. Saka, "Kinetics of transesterification in rapeseed oil to biodiesel fuel as treated in supercritical methanol," Fuel, vol. 80, no. 5, pp. 693-698, 2001.

[15] X. Liu, H. He, Y. Wang, and S. Zhu, "Transesterification of soybean oil to biodiesel using $\mathrm{CaO}$ as a soild base catalyst," Fuel, vol. 87, pp. 216-221, 2008.

[16] M. C. Math and G. Irfan, "Optimization of restaurant waste oil methyl ester yield," Journal of Scientific and Industrial Research, vol. 66, no. 9, pp. 772-776, 2007. 
[17] N. Prakash, A. A. Jose, M. G. Devanesan, and T. Viruthagiri, "Optimization of Karanja oil transesterification," Indian Journal of Chemical Technology, vol. 13, no. 5, pp. 505-509, 2006.

[18] P. D. Patil and S. Deng, "Optimization of biodiesel production from edible and non-edible vegetable oils," Fuel, vol. 88, no. 7, pp. 1302-1306, 2009. 


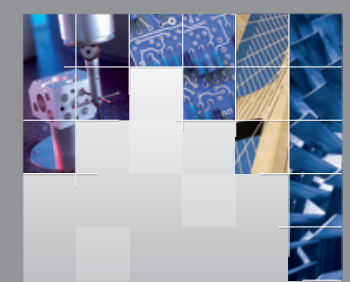

\section{Enfincering}
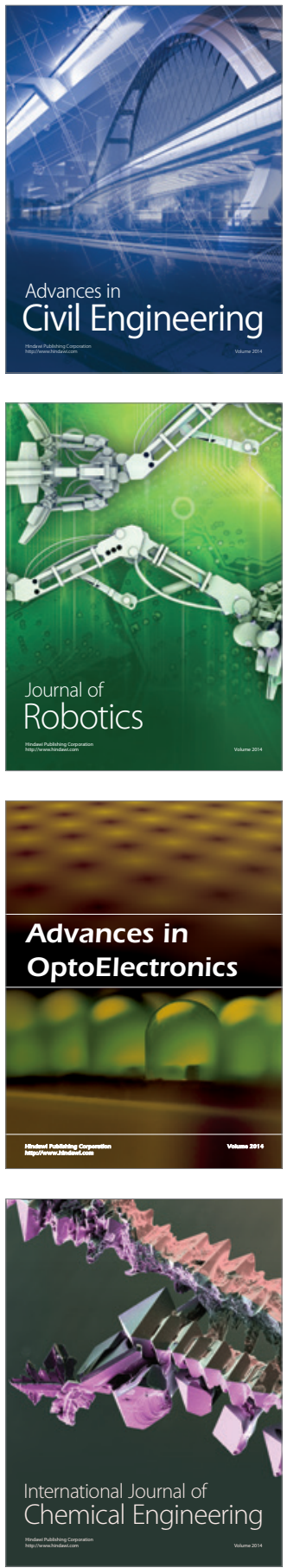

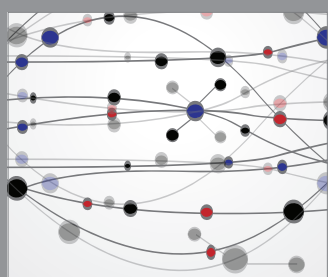

The Scientific World Journal

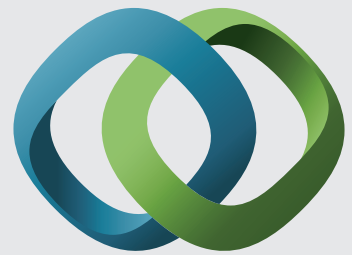

\section{Hindawi}

Submit your manuscripts at

http://www.hindawi.com
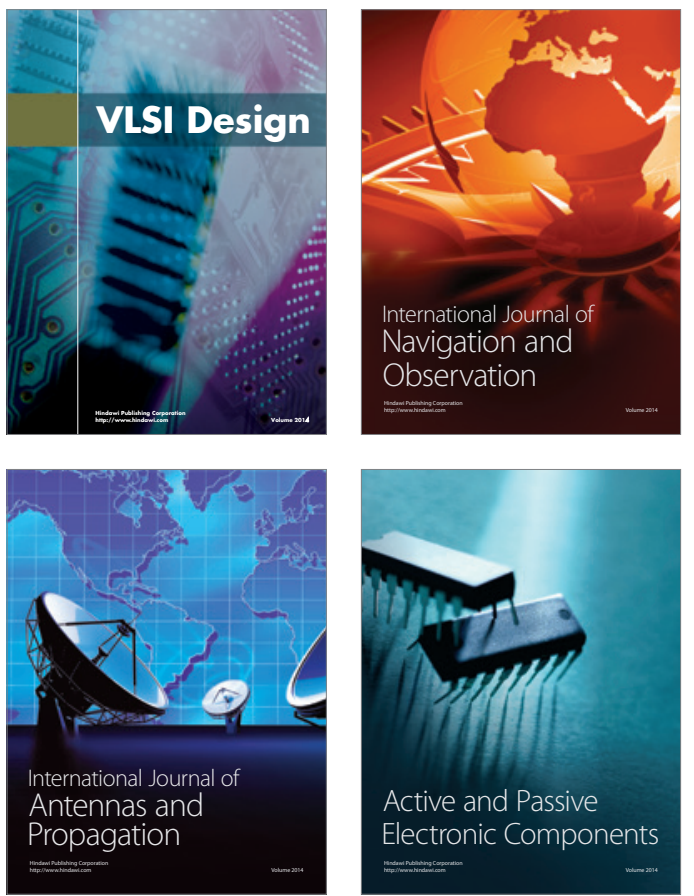
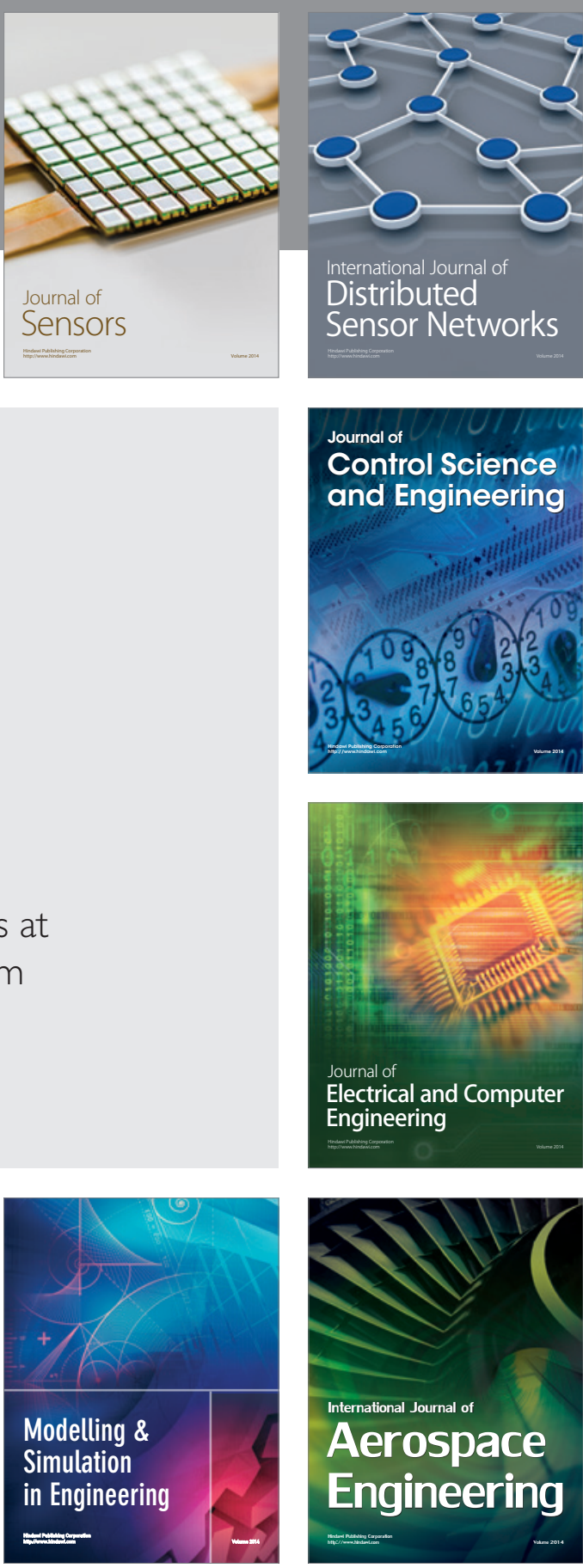

International Journal of

Distributed

Sensor Networks

Journal of

Control Science

and Engineering
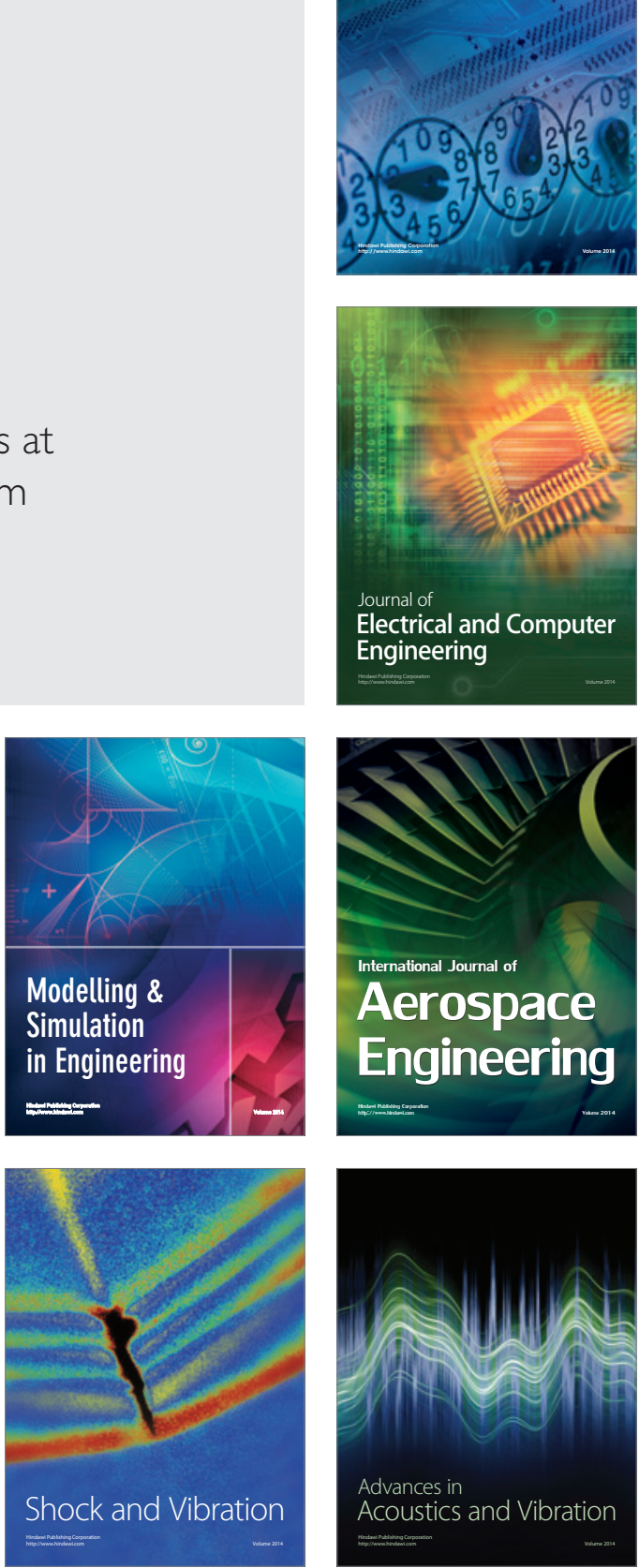